\title{
Capiteles jónicos de aire corintizante en Cartagena
}

\author{
Sebastián F. RAMALLO ASENSIO ${ }^{1}$ \\ Universidad de Murcia
}

\begin{abstract}
Resumen
En este artículo se analizan tres capiteles singulares hallados en Cartagena y otro en Portmán. Todos ellos muestran unos rasgos comunes que les proporcionan cierto aire de familia aunque no se pueden atribuir a la misma mano. Se caracterizan por introducir motivos desarrollados en el capitel corintizante sobre la arquitectura propia del jónico y son un testimonio más de la complejidad y variedad de la decoración arquitectónica de la ciudad de Carthago Nova, donde el orden jónico, sobre todo en su variante de cuatro caras iguales y volutas en diagonal, adquiere una especial relevancia. Carecen de contexto preciso, lo que dificulta su datación, que no obstante podría entrar dentro de la primera mitad del siglo I d.C.
\end{abstract}

Palabras Clave: Carthago Nova, capitel, jónico, corintizante, arquitectura, tardohelenismo, travertino.

\section{Summary}

In this paper four singular capitals found in Cartagena and Portmán are analyzed. All of them show some common features that provide them certain family resemblance, thougt they cannot attributed to the same hand. They are characterized for introducing motives developed in the "corintizante" capital on the ionic capital and they are a testimony of the complexity and variety of the architectural decoration in the city of Carthago Nova, where the ionic order, especially in its variant of four equal sides and volutes in diagonal, acquires a special relevancy. There is a lack of a precise context, which impedes its dating, which could however be considered as part of the first half of the 1st century A.D.

Keywords: Carthago Nova, capital, ionic, corinthian, architecture, Late-hellenistic, travertine.

\section{INTRODUCCIÓN}

La precoz e intensa romanización de Carthago Nova y su entorno estimulada, entre otras causas, por la presencia masiva de inmigrantes itálicos, especialmente procedentes de las áreas centro y sur itálicas, se manifiesta en el plano arquitectónico y monumental por la rápida trasposición de

1 Departamento de Prehistoria, Arqueología, Historia Antigua, Historia Medieval y Ciencias y Técnicas Historiográficas - Facultad de Letras. Universidad de Murcia - C/ Santo Cristo, 1, 30001-Murcia

* Este trabajo se ha realizado en el marco del Proyecto de Investigación: Carthago Nova y su territorium: modelos de modelos edilicios, técnicas, materiales de construcción, y sistemas decorativos de clara raigambre itálica, que están ya atestiguados a finales del siglo II a.C., mientras que en el registro arqueológico este proceso se refleja en la abundancia de producciones cerámicas de fabricación itálica y mediterráneas ${ }^{*}$. Destacan entre ellas las cerámi- ocupación en el sureste de Iberia entre época tardorrepublicana y la Antigüedad Tardía (HAR2008-06115) del Ministerio de Ciencia e Innovación, (Subdirección General de Proyectos de Investigación) que es subvencionado parcialmente con Fondos FEDER. 
cas de barniz negro, las ánforas vinarias Grecoitálicas y Dressel 1A y las producciones apulas Lamb.2 (Molina, 1997: 70-73). Son la contrapartida a la explotación y exportación masiva de los recursos metalíferos obtenidos en el entorno; el pecio del Mal di Ventre, sumergido frente a la costa occidental de Cerdeña y con un cargamento de casi un millar de lingotes de plomo (Salvi, 1992a y 1992b) es el testimonio más excepcional de ese intenso trasiego, que alcanza su punto culminante en la primera mitad del siglo I a.C. El mismo carácter de base naval del ejército romano y los movimientos de población propios de su carácter portuario debieron acrecentar la importación de mercancías, no sólo destinadas a la población de la propia ciudad, sino también a satisfacer las necesidades de los numerosos focos de extracción de los recursos mineros distribuidos por todo el entorno de Carthago Nova y Mazarrón.

Todo este dinamismo comercial impulsa procesos de renovación urbana en los que los órdenes toscano y jónico van a adquirir un especial protagonismo. El primero es utilizado en los pórticos que dotan de un aspecto monumental al frente marítimo situado en el flanco occidental de la ciudad, como atestiguan los restos de Morería Baja y Palacio de Riquelme. El segundo debió pronto ser empleado para construcciones de mayor entidad a juzgar por las dimensiones y cuidada labra de algunos ejemplares. La suma de ambos, junto a la cronología precoz, es la mejor evidencia de una actividad edilicia que tiene entre mediados del siglo I a.C. y el comedio de la centuria siguiente su momento culminante.

En esta vasta producción trabajada sobre caliza grisácea en un primer momento $\mathrm{y}$, sobre todo para los elementos jónicos, en travertino rojo a partir de época augustea, destaca la serie de capiteles asimilables -aunque no idénticos- al tipo jónico-itálico, ampliamente desarrollado en distintas regiones de Italia durante los siglos III-I a.C.(Ramallo, 2004: 156-170). Pero además, llama la atención una variante muy singular que no responde a los esquemas propios del orden jónico, aunque utiliza su arquitectura, sino que, al contrario, incorpora ciertos motivos del orden corintio. Se trata de un conjunto de cuatro capiteles que hemos definido como jónicos de aire corintizante, ya que adoptan elementos de ambos órdenes, y que M. Trunk denomina jonizantes. Su concentración en Carthago Nova, nos permite, de momento, vincularlos a talleres activos en la ciudad en época, probablemente, augusteo/julioclaudia, que no obstante, pudieron desarrollar también su actividad, o difundir sus modelos, en el ámbito del conventus carthaginiensis como parecen mostrar los ejemplares de Segobriga, ciudad con la que la capital debió mantener una estrecha relación a través de la vía interior (Abascal y Lorrio, 1999: 561-568). El problema que plantean estos capiteles, como la mayor parte de los ejemplares encontrados en Cartagena, salvo los del teatro y algunos pocos más, es que no pueden atribuirse a un edificio conocido, y que, además, carecen de un contexto arqueológico preciso para afinar en su datación. De ahí los problemas que se han planteado con su estudio.

El primer ejemplar que se puede asignar a este grupo fue hallado en 1969 en las excavaciones de la Huerta del Paturro de Portmán, al parecer desplomado sobre una de las habitaciones principales, a juzgar por una fotografía que estuvo en su día expuesta en el Museo Arqueológico de Cartagena. Al margen de este dato no existe memoria arqueológica publicada de las excavaciones ni tampoco informe alguno en el Museo Arqueológico de Murcia. Los trabajos fueron dirigidos por M. Jorge Aragoneses, con la ayuda de Pedro A. San Martín. El capitel se conserva expuesto en el Museo de Murcia, n. de inventario: 4536. El material sobre el que está labrada la pieza corresponde a un mármol de textura y características similares al extraído en el Cabezo Gordo, ampliamente utilizado en la antigüedad y bien representado en la villa de Portmán. Fue publicado por Gutiérrez Behemerid (1992: 35), datándolo en época severiana. Poco después, Martínez Rodríguez lo incluyó en su tesis de licenciatura, considerando, por el contrario, una datación del siglo I d.C. y relacionándolo con la serie de capiteles recogidos por Ronczewski (1923) dentro de su variante D. Fernández (1999: 97; 2003: 77-78), por su parte, lo recoge también en su estudio de conjunto sobre la villa del Paturro, procurando una datación de mediados del siglo II. Analiza además el resto de materiales, entre los que destacan mármoles de distintas procedencias, fragmentos escultóricos, terracotas y, sobre todo un abundante lote de cerámicas finas, con un porcentaje muy elevado 
de sigillatas sudgálicas y africana A, recuperadas en su mayor parte en el interior de dos grandes balsas revestidas de mortero hidráulico para las que se han dado distintas interpretaciones. La villa tiene una primera fase en época republicana, probablemente vinculada a actividades mineras, para alcanzar un desarrollo más monumental durante los siglos I y II, siendo destruida a finales del siglo II. A la última fase corresponde el mosaico policromo del triclinum, con la representación de un busto femenino de frente, enmarcado en un cuadrado flanqueado arriba y abajo por otros dos cuadros con sendos pavos reales en posición frontal y con las alas desplegadas. Con la información arqueológica disponible es difícil establecer una datación segura para el capitel, ya que puede corresponder a la remodelación monumental de la villa a comienzos del siglo I, o a alguna remodelación posterior. El capitel tiene una altura de $30 \mathrm{~cm}$, y una anchura máxima de $44 \mathrm{~cm}$, con una diagonal de $60 \mathrm{~cm}$. Presenta un grueso ábaco en forma de tablero cuadrangular, formado por un ancho listel sobre caveto, que remata la pieza por su parte superior y la recubre prácticamente en todo su perímetro. La cara frontal (Lam. 1) está formada por dos anchas bandas onduladas, contrapuestas y simétricas, que terminan en una doble espiral en los extremos, la superior en forma de volutas y las inferiores, de menor tamaño unidas en el centro por un doble cordón. Dos semipalmetas de cuatro lóbulos, paralelas a las cintas exteriores, apuntadas en los extremos, brotan del giro de las hélices inferiores y constriñen un fruto en forma de piña que marca el eje central de la composición y se prolonga en lo alto en un delgado tallo que termina en una sencilla hoja acorazonada dispuesta bajo el borde inferior del ábaco. En el extremo opuesto, se colona una hoja triangular invertida. En las caras laterales, dos hojas de acanto verticales y superpuestas señalan el eje central, la superior forma el balteus, mientas que de la infrapuesta, superpuesta al kalathos brota un tallo ondulados a ambos lados que termina en seis pétalos lanceolados, agrupados en dos grupos de tres, que ocupan el

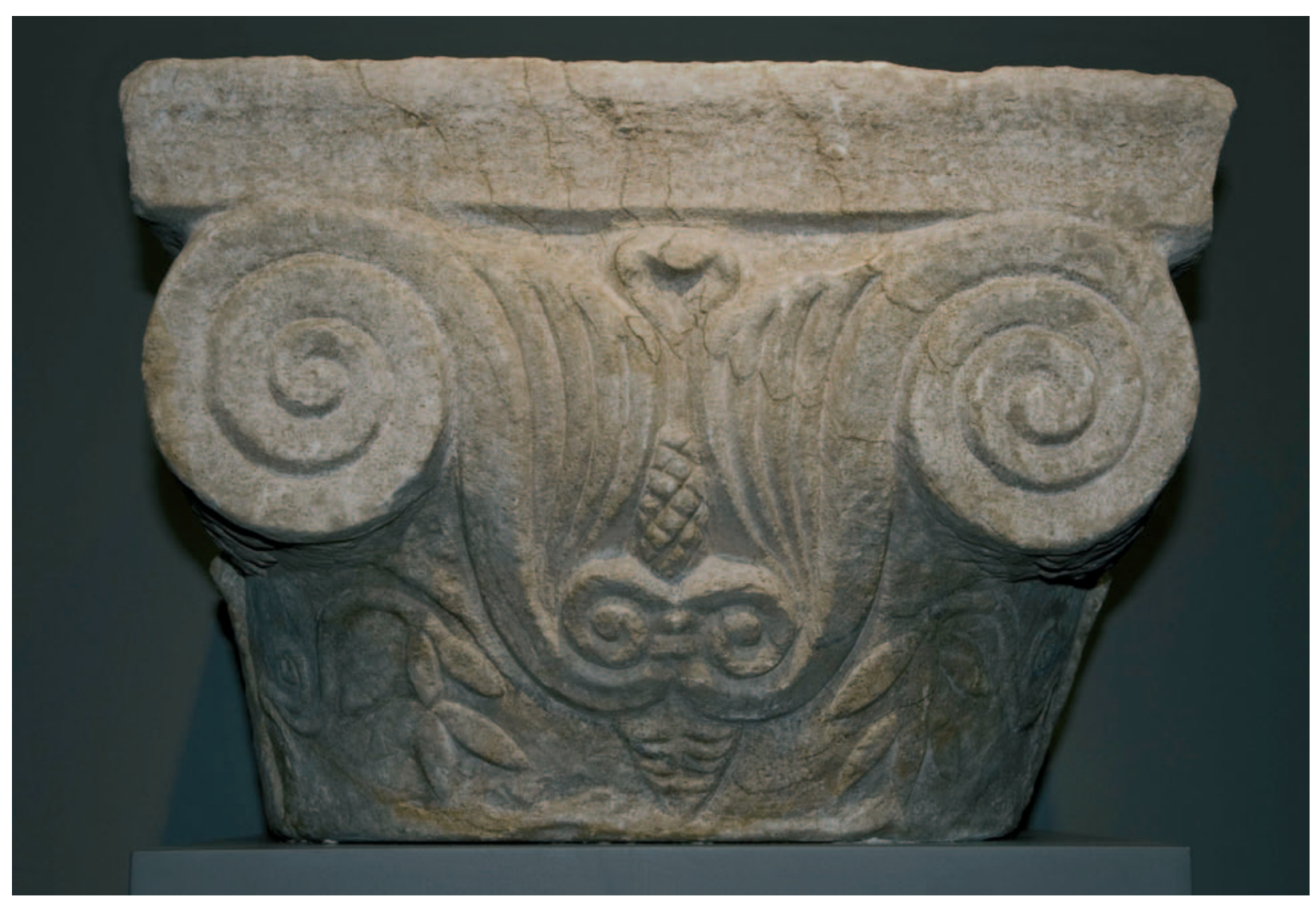

Figura 1. Cara frontal del capitel jónico con volutas en S hallado en la Huerta del Paturro (Portmán). 


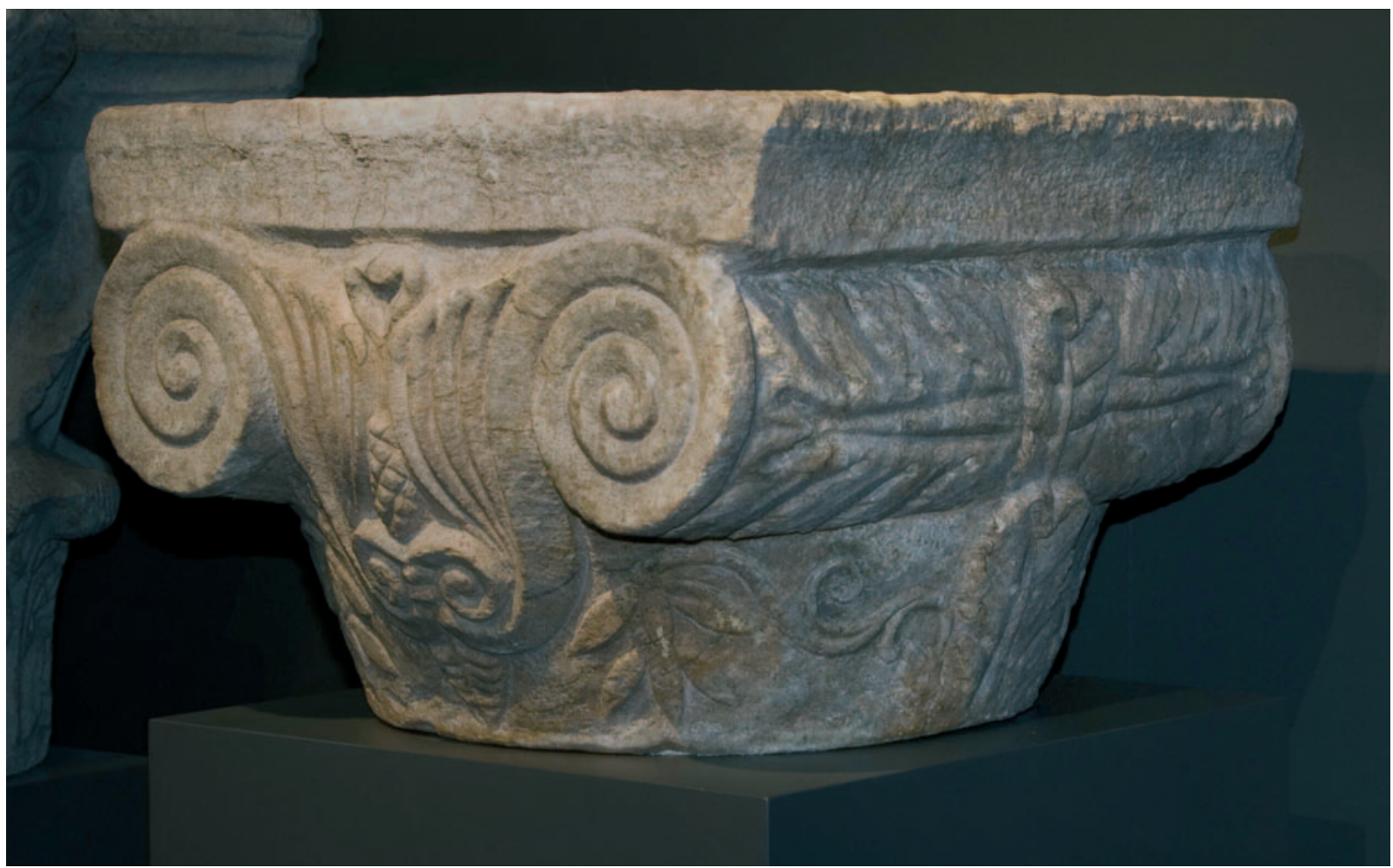

Figura 2.- Lateral del capitel jónico con volutas en S hallado en la Huerta del Paturro (Portmán).

espacio frontal situado bajo las volutas (Lam. 2); otros dos tallos menores terminan en espiral. Los pulvinos están recubiertos por dos hojas acantizantes contrapuestas, atravesadas por una nervadura central que se ensancha hacia la base y con lóbulos estrechos y muy alargados (Gutiérrez, 1992: 35).

El segundo capitel de este mismo tipo, por seguir un orden cronológico en cuanto a la fecha del hallazgo, procede del desmonte y desescombro de las estructuras modernas de lo que se conocía como Puerta de la Villa, explanada situada en la ladera occidental del Cerro de la Concepción, a espaldas de la cavea del teatro. Fue hallado en 1999 y está labrado en travertino rojo. Presenta un alto grado de erosión y deterioro, debido a su reutilización en una fábrica moderna. Ha perdido el ábaco y una de las volutas con el correspondiente pulvino. Las dimensiones conservadas son: $54 \mathrm{~cm}$ de anchura máxima en la cara frontal, con una altura de $30 \mathrm{~cm}$, mientras que el pulvino tiene una longitud de $46 \mathrm{~cm}$. El diámetro del sumoscapo, separado del capitel por un listel liso, es de $42 \mathrm{~cm}$ (Ramallo, 2004: 205-206). Un astrágalo, liso y formado por estrecho listel y baquetilla, separa el capitel del extremo superior del fuste labrado en el mismo bloque. En la cara frontal se dibujan dos semipalmetas de cuatro lóbulos divergentes y simétricas en las cuales el exterior, con los bordes realzados, adquiere un gran desarrollo formando dos cintas onduladas de forma serpentiforme que determinan dos grandes volutas en el extremo superior y dos pequeñas espirales o hélices en el inferior, anudadas en el centro del capitel. Del punto de unión nace un cáliz, que marca el eje axial y se bifurca en una horquilla en forma de V. El alto grado de deterioro de la mitad superior del capitel, impide saber el motivo que brotaba de este cáliz, aunque parece intuirse la existencia de algún fruto. Tres lóbulos flameantes a cada lado completan la composición central. Del giro de las volutas superiores nace un delgado tallo ondulado rematado en tres hojas lanceoladas (Lam. 3). En el lateral, los pulvinos aparecen recubierto por dos hojas acantiformes contrapuestas formadas por lóbulos esquematizados que se desarrollan desde dos hojas de acanto superpuestas que constituyen el balteus, aunque la fuerte erosión que presenta impide concretar su forma (Lám. 4).

El tercer capitel, siguiendo el orden cronológico de los hallazgos, fue recuperado en el año 2004 


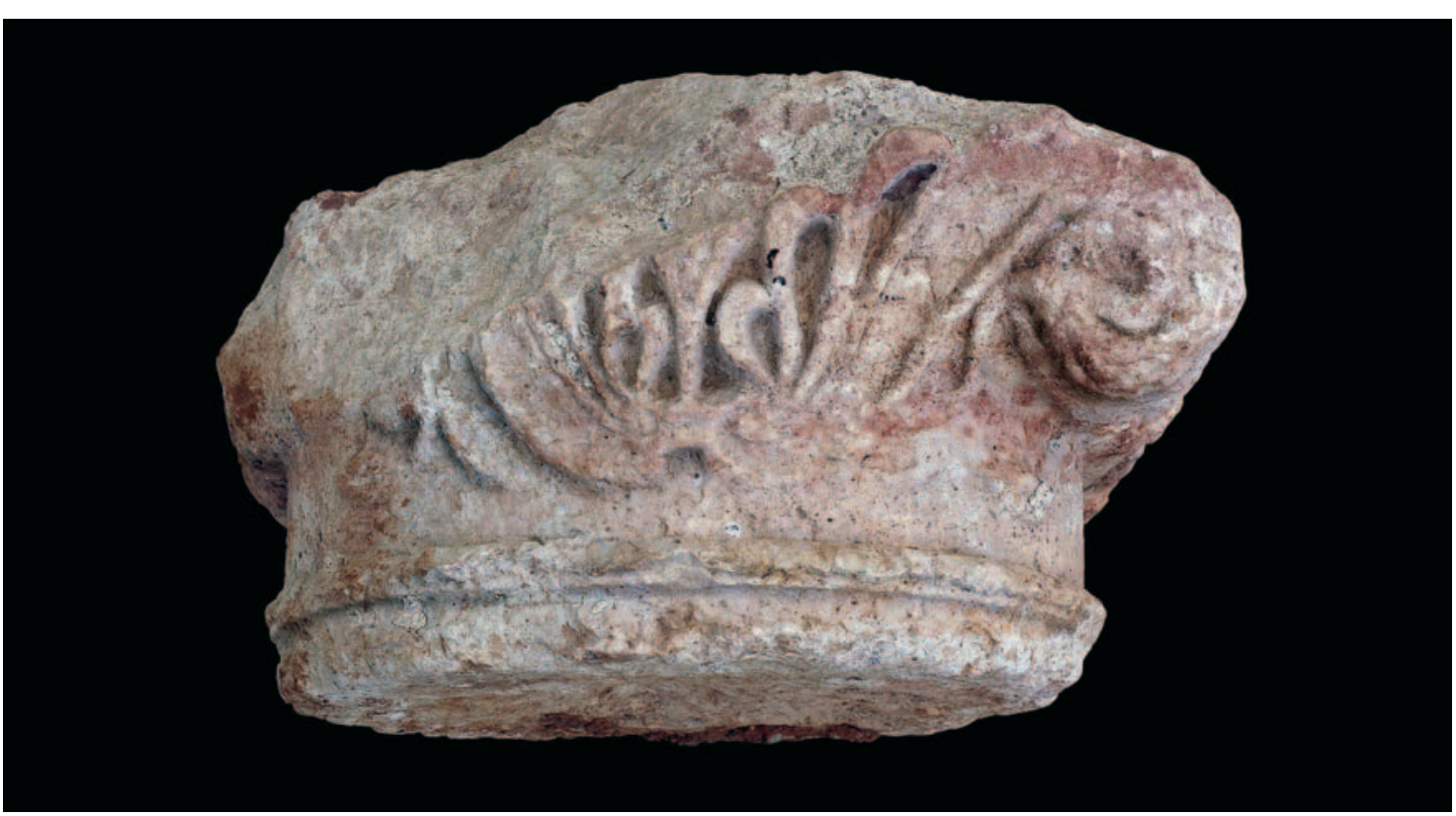

Figura 3. Cara frontal del capitel hallado en la Puerta de la Villa.

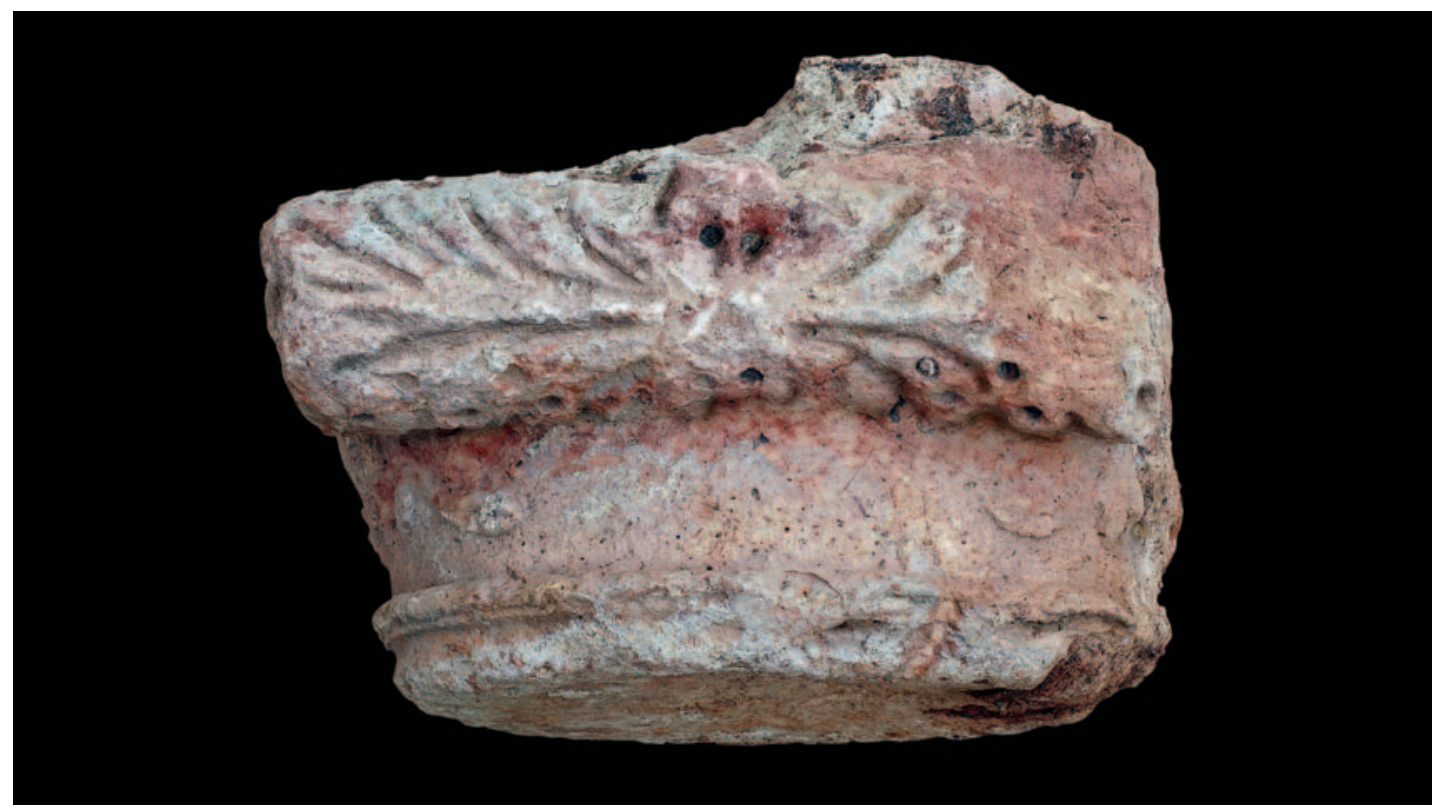

Figura 4.- Lateral del capitel jónico hallado en la Puerta de la Villa.

en un solar de la calle Balcones Azules, esquina Ignacio García, situado en la falda meridional del Cerro del Molinete, en una zona próxima al área forense $\mathrm{y}$, a la vez cercana a las termas de la $\mathrm{C}$ / Honda. Había sido reutilizado, junto a un fragmento de fuste de travertino rojo, en un muro de contención de una fosa tardía, por lo que no se puede establecer su ubicación original. En la misma parcela se han descubierto también otros elementos arquitectónicos descontextualizados o reempleados en construcciones tardorromanas, junto a placas de mármol de diferentes colores (García Lorca, 2005: 275-276). La pieza está labrada en travertino rojo extraído, probablemente, de las canteras de Mula y se conserva en el Museo Arqueológico Municipal, con el número de inventario BA-1010-201-1. La altura total es de $47 \mathrm{~cm}$ y su anchura en el ábaco de $60 \mathrm{~cm}$ con una diagonal de $86 \mathrm{~cm}$. El ábaco mide $9 \mathrm{~cm}$ de altura, de los cuales $1,5 \mathrm{~cm}$ corresponde a la franja inferior separada del resto por una arista y ligeramente rehundido. Sólo una de las caras fronta- 
les conserva trazas del kyma jónico, compuesto por anchas semiovas contorneadas por esgucios facetados y separadas por lancetas de las que se reconoce la punta inferior. Caveto y listel completan un grueso ábaco en forma de tablero cuadrangular que cubre por completo el cuerpo del capitel. El equino tiene una altura de $21 \mathrm{~cm}$ y descansa sobre un grueso astrágalo de $3 \mathrm{~cm}$ formado por gruesas cuentas ovaladas separadas por discos lenticulares, superpuesto a una moldura en forma de bisel, que sirve para diferenciar el capitel del extremo superior del fuste liso que tiene una altura de $15 \mathrm{~cm}$. Sobre el equino dos cintas onduladas de sección cóncava y bordes realzados determinan en el extremo superior las gruesas volutas dispuestas bajo los extremos del ábaco, con una roseta de cuatro pétalos en el óculo, y se enrollan en el inferior en otras dos volutas simétricas y de menor tamaño, trabadas por un listel horizontal moldurado, de donde nacen cuatro estilizadas semipalmetas flameantes que se desarrollan en vertical, apoyando sus extremos apuntados cada una sobre la contigua. En el eje axial brota un fruto o motivo heráldico en forma de ocho que se prolonga en el extremo inferior apuntado. En el vértice de unión de la cinta con el giro externo de la voluta brota un cáliz del que surge una estilizada flor de cinco pétalos (Lam. 5). Una de las caras laterales ha perdido la mitad del pulvino y el balteus, aunque tiene casi integra la hoja de acanto con nervadura central apuntada y los lóbulos cuyas digitaciones se unen formando profundos triángulos. La cara opuesta conserva el balteus con dos hojas verticales de acanto superpuestas y las hojas acantizantes horizontales contrapuestas y divergentes que recubren el cilindro, cuyos lóbulos están separados por profundas acanaladuras (Lám. 6). La otra cara frontal ha perdido la voluta derecha. Destaca en ella sobre todo los fuertes contrastes de luces y sombras resaltados por los profundos y anchos surcos que separan las semipalmetas y también los distintos giros de las volutas. En este frente las espirales de la base están atravesadas por acanaladuras que se prolongan para determinar las semipalmetas (Ramallo, 2009: 147-148 y Noguera et alii, 2009: 221).

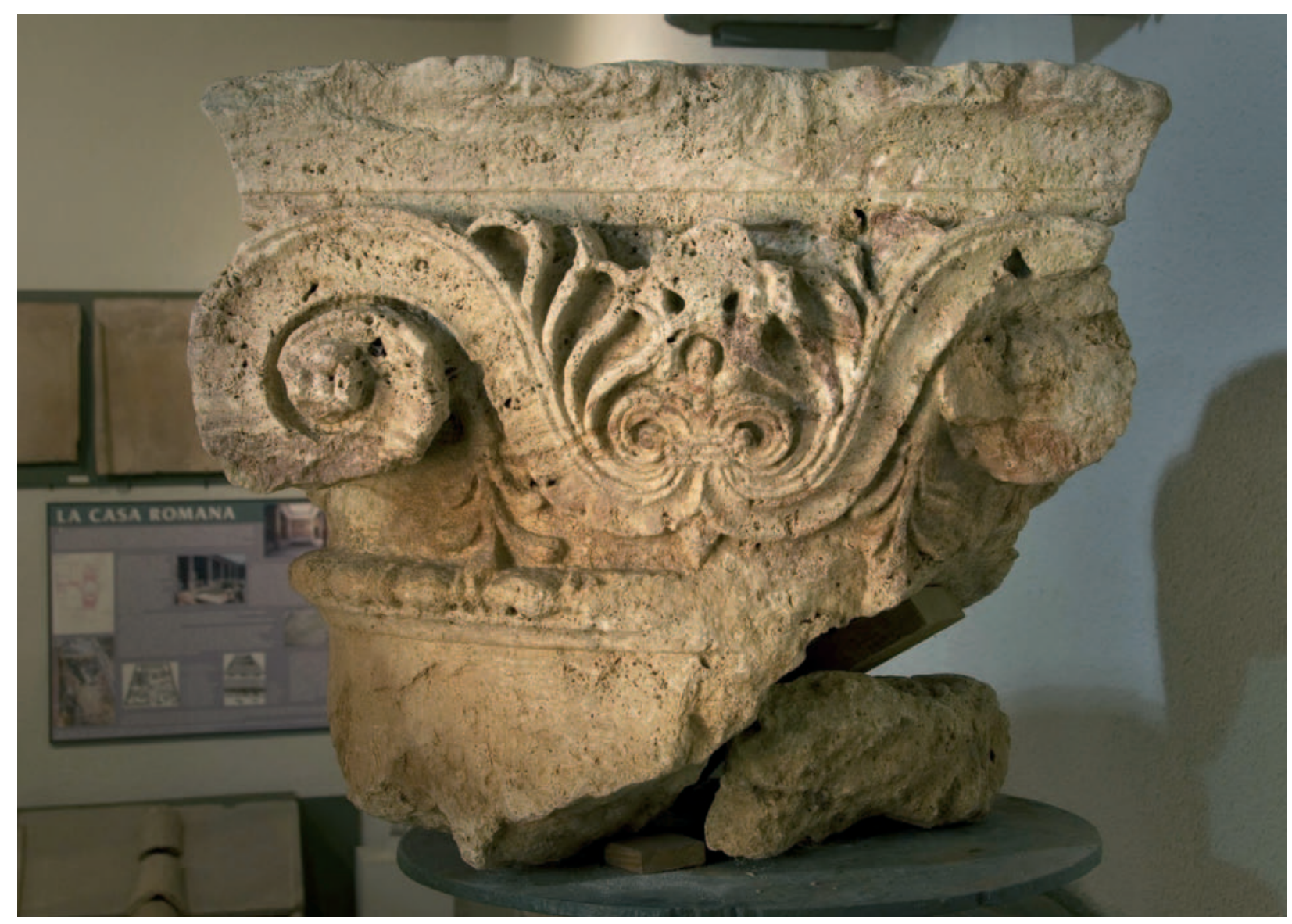

Figura 5. Cara frontal del capitel jónico hallado en Balcones Azules. 


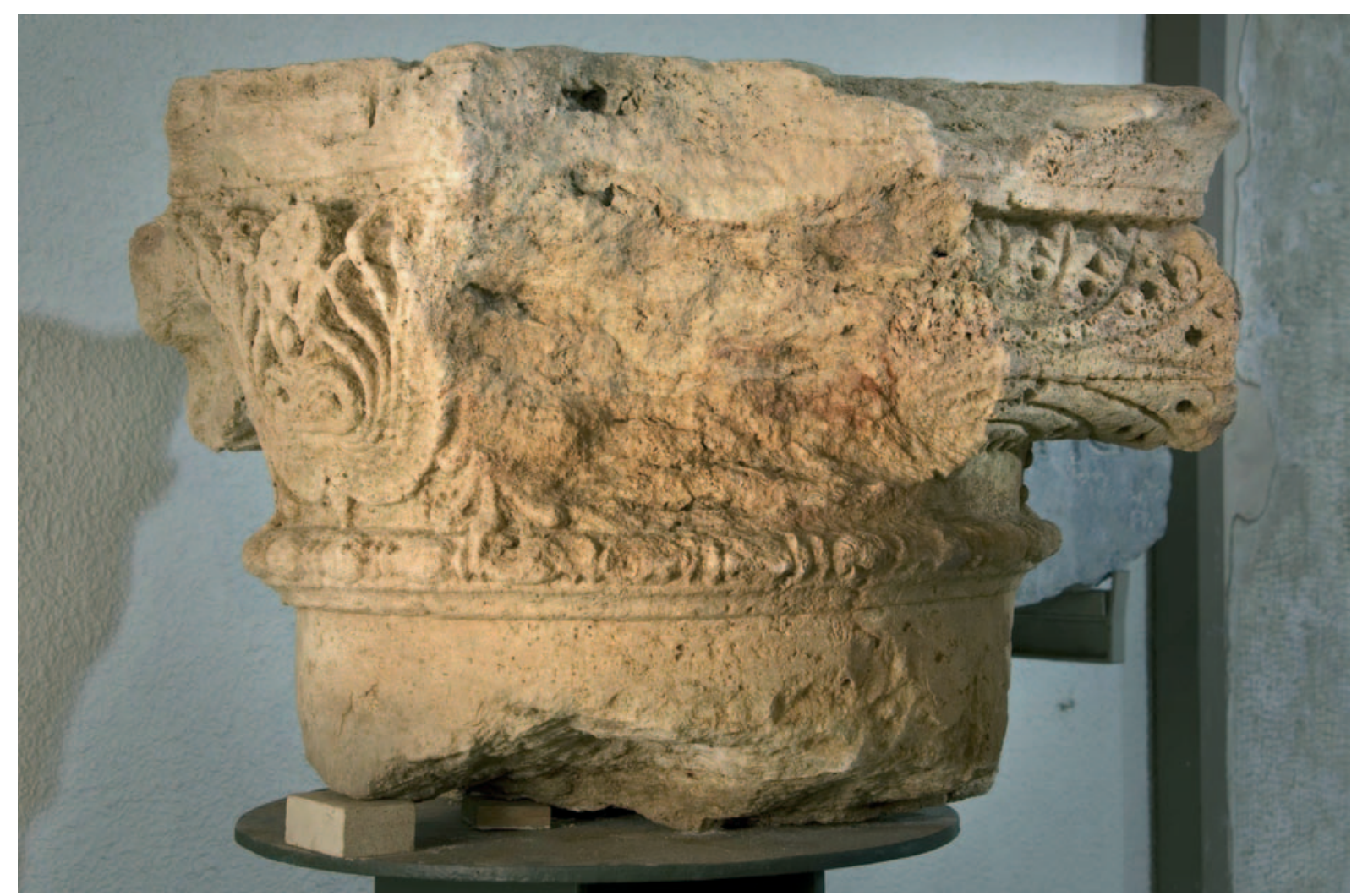

Figura 6.- Lateral del capitel jónico hallado en Balcones Azules.

El último, hasta ahora, de estos capiteles, apareció desplomado sobre el suelo de la denominada "estancia I", en un solar de la calle Honda $\mathrm{n}^{\circ} 7$, situado en la falda meridional del Cerro del Molinete, próximo por tanto al área foraria y en el lado opuesto al complejo termal de la calle Honda (Fernández, Zapata y Tercero, 2007). En origen debió estar asociado a un ámbito de carácter doméstico. Se conserva en el Museo Arqueológico Municipal con el número de inventario 4352. Está labrado en travertino rojo, material extraído, probablemente, de las canteras del Cerro de la Almagra (Mula). Tiene una altura de $30 \mathrm{~cm}$, el lado del ábaco mide $52 \mathrm{~cm}$ y la diagonal es de $73 \mathrm{~cm}$. El ábaco se divide en un óvolo de $2,5 \mathrm{~cm}$ y el caveto de $6,5 \mathrm{~cm}$.

El ábaco está decorado en su borde superior con un kyma jónico de semiovas muy anchas bordeadas por esgucios entrelazados; no se aprecian las típicas puntas de lanza de separación. Este motivo ornamental se conserva sobre todo en una de las caras laterales, aunque también es visible, pero más erosionado en las restantes. Sigue un caveto dividido en dos partes por una ranura que define una franja recta en la parte inferior y más ancha y ligeramente cóncava en la superior. En la cara frontal, bajo el ábaco se desarrollan dos cintas onduladas en forma de $S$, que se estrechan hacia la base donde se unen por un listel horizontal mientras que en el extremo opuesto se enrollan determinando las volutas, con el óculo ocupado por una roseta formada por cuatro pétalos de forma arriñonada distribuidos en torno a un botón central. En la zona central brotan desde el extremo inferior de la cinta cóncava cuatro semipalmetas flameantes contiguas y conectadas en el extremo superior. En el eje axial y desde el punto de unión de las espirales inferiores emerge un fruto en forma de estilizada bellota que constituye, a su vez, el centro de una flor de cuatro pétalos que ocupa todo el espacio disponible entre los lóbulos de las semipalmetas (Lam. 7). En el cojinete lateral, el balteus está formado por dos hojas de acanto superpuestas de cinco lóbulos de tres digitaciones. El pulvino está revestido por frondosas hojas contrapuestas que se desarrollan a partir de un nervio central que se ensancha hacia la base y termina en tres hojas lanceoladas; el contacto de las digitaciones determina zonas de 


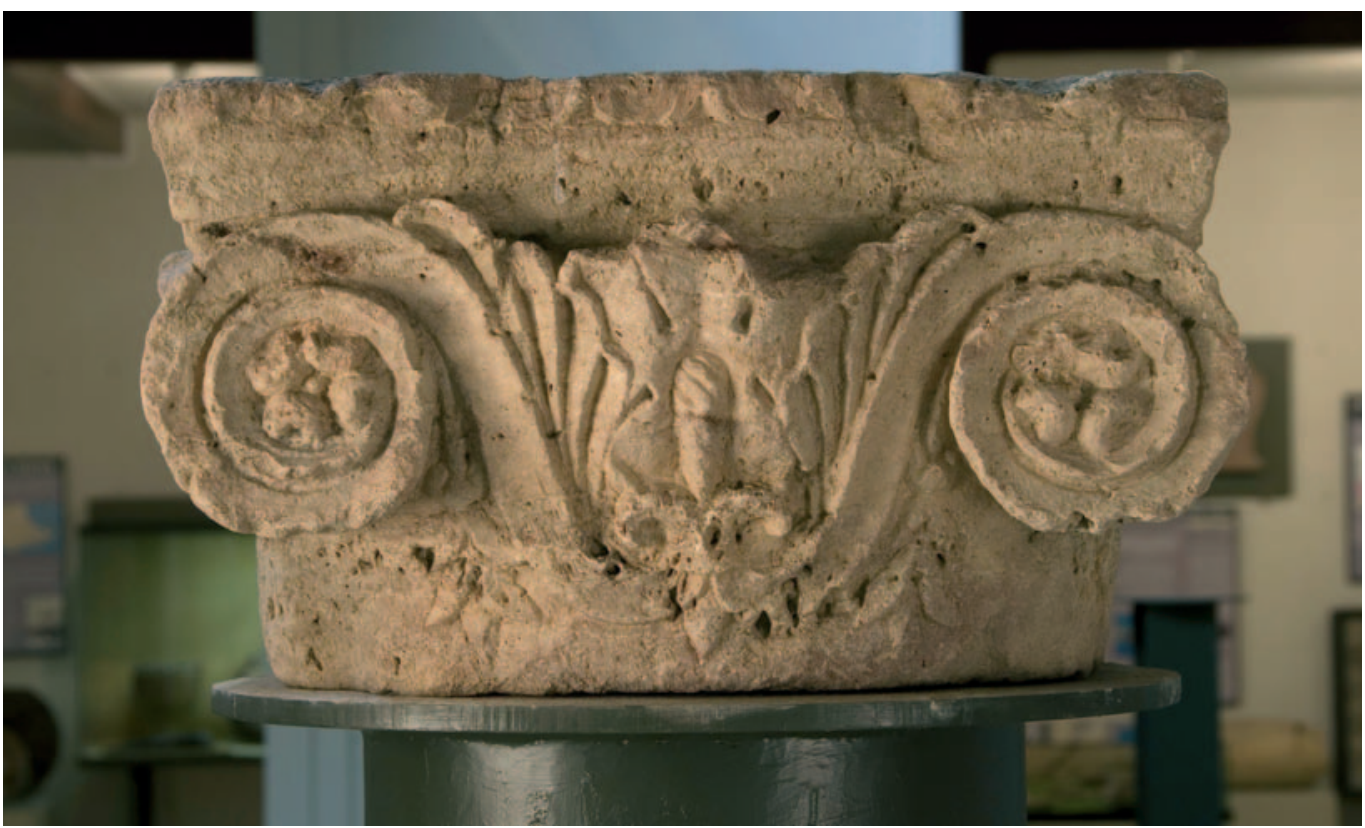

Figura 7. Cara frontal del capitel jónico hallado en C/ Honda n. 7.

sombra en forma de triángulo alargado (Lám. 8). El pulvino termina en los extremos en un grueso reborde y la decoración recubre por completo el cojinete, prolongándose por la superficie inferior. Del vértice de unión entre la cinta y el primer giro de la voluta brota un tallo grueso con un cáliz de tres sépalos invertido y un tallo del que penden cinco hojas. La cara opuesta a la frontal conserva sobre el ábaco trazas de las ovas sobre el óvolo y las dos volutas formadas por el desarrollo espiraliforme de las cintas que decoraban el equino de las cuales se conserva solo la impronta, habiendo desaparecido las semipalmetas y el fruto central. También se observa con nitidez el tallo derecho con las hojas, que brota desde el vértice superior de la voluta, mientras que el opuesto se halla más erosionado. El lateral reproduce el balteus con las dos hojas de acanto superpuestas y el pulvino con las hojas acantiformes contrapuestas. En esta cara y bajo el pulvino existe una gruesa concavidad natural de $3 \mathrm{~cm}$ de diámetro y numerosas vacuolas de menor tamaño visibles también en las otras caras del capitel y sobre todo en las partes lisas bajo los pulvinos.

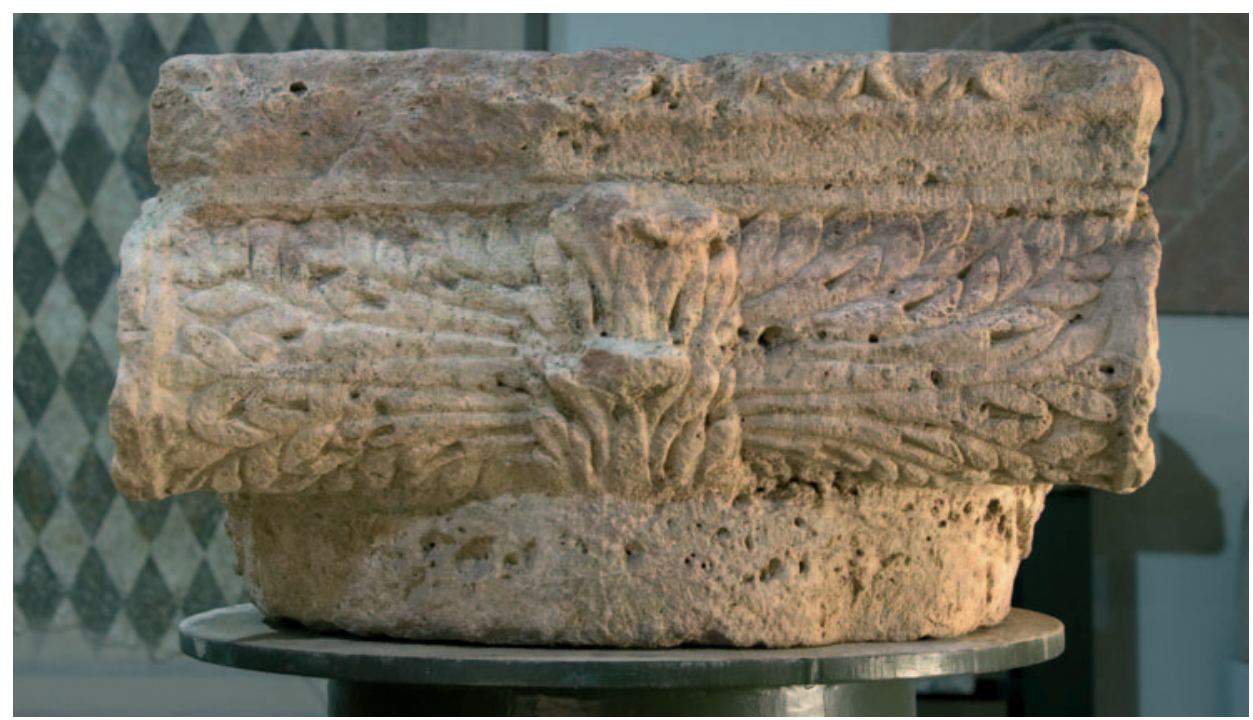

Figura 8. Lateral del capitel jónico hallazo en C/ Honda n. 7. 


\section{ESTUDIO}

En el ámbito de los capiteles romanos canónicos, la serie aquí estudiada constituye un híbrido entre el tipo jónico y los denominados corintizantes, ya que incorpora elementos característicos de estos últimos a la arquitectura propia del primero. En los cuatro ejemplares aquí recogidos hay algunos elementos comunes, que lo son también, no obstante, de parte de los capiteles jónicos de Cartagena, en el ámbito de una tradición local, que va más allá de la identidad del soporte pétreo. Tales son el ábaco macizo y cuadrado, que es común a los capiteles jónicos con cuatro caras iguales y volutas en diagonal, definidos tradicionalmente como jónico-itálicos, el grueso astrágalo de cuentas y discos sobre el que apoya el equino, también frecuentes en la serie anterior, y que sirve para separar el capitel del sumoscapo del fuste, que vemos en las piezas de Puerta de la Villa y Balcones Azules, el material en el que están labrados, travertino rojo, y la decoración del pulvino, con el balteus en forma de hoja - o doble hoja- de acanto (Lám. 9). Aunque en ningún caso son idénticos, por lo que, en principio, no se pueden asociar a un mismo edificio, todos ellos tienen un aire de familia que permite atribuirlos sino al mismo taller, si a artesanos con una formación similar o que han manejado modelos muy próximos. Sólo el ejemplar de la Huerta del Paturro muestra algunas diferencia, al margen del material, como es la ausencia de collarino en la base, del que carece también el capitel de Calle Honda, y un menor relieve en la ejecución, lo que determina superficies más planas y un menor contraste de luces y sombras, efectos especialmente acentuados en los capiteles de Balcones Azules y Puerta de la Villa.

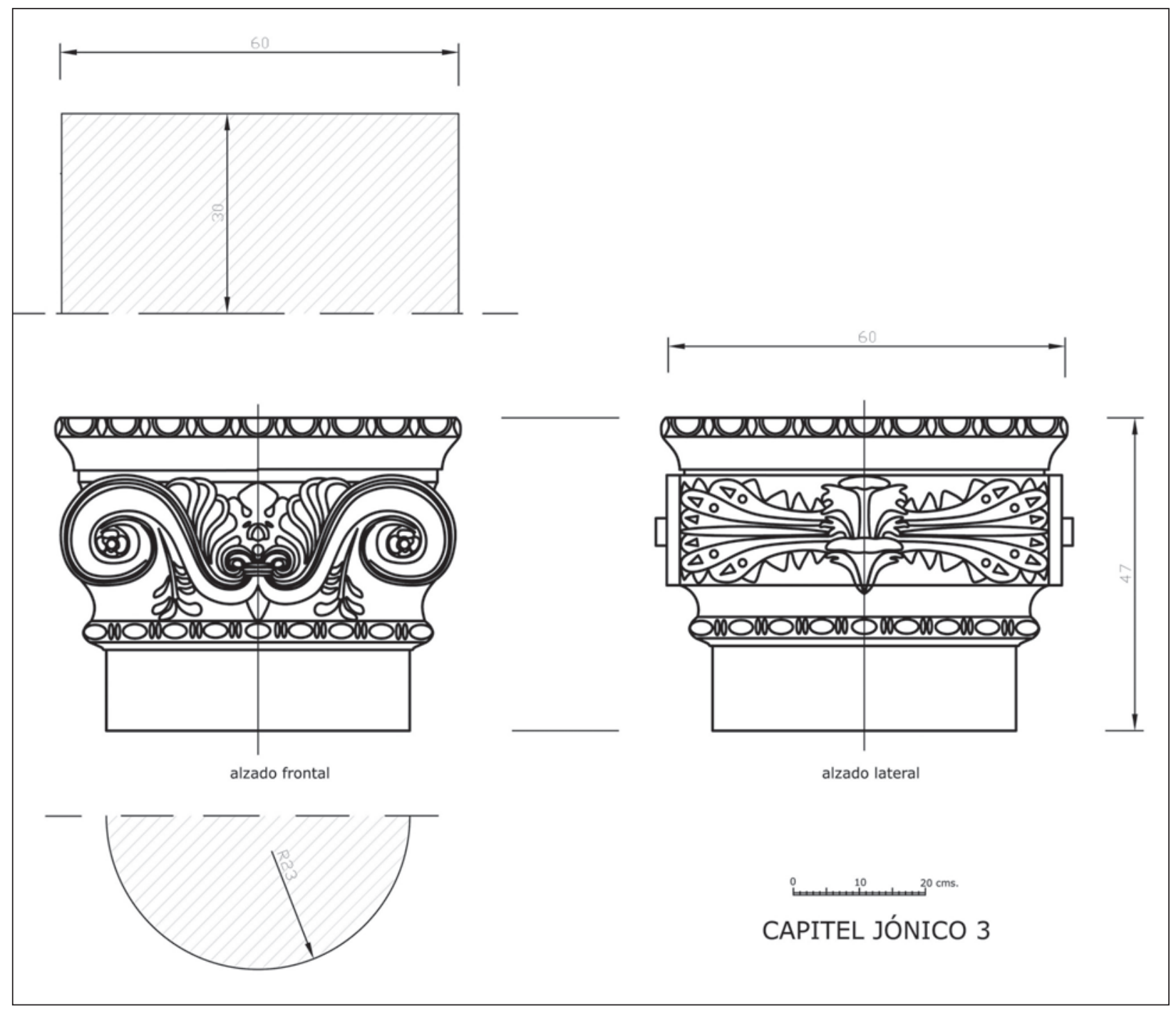

Figura 9. CApitel jónico de Balcones Azules. Alzado frontal y lateral. 
El problema se plantea a la hora de buscar posibles prototipos o fuentes de inspiración. En este sentido, hay que señalar que este tipo de capitel es bastante raro en la Península Ibérica. Al margen de las piezas de Cartagena, y con esquema de volutas en doble $\mathrm{S}$ aplicado sobre capitel jónico, se han señalado dos ejemplares en Tarragona, fechados en época tardo-republicana/augustea (Gutiérrez, 1992: 29-30), si bien en este caso muestran notables diferencias respecto a los de Carthago Nova, comenzando por la aplicación de esquemas distintos en las caras frontales y laterales. En este caso, mientras que la cara frontal muestra el equino característico del capitel jónico con tres ovas, colocado sobre una doble fila de hojas triangulares esquemáticas, los laterales presentan sendas cintas onduladas con los extremos enrollados, enfrentadas y dispuestas horizontalmente y que se adaptan al espacio del pulvino, encontrándose en el centro (Gimeno, 1971: 770-772, nn. 1217 y 1218). Los otros dos ejemplares, datados en el siglo III, proceden de Zaragoza y Astorga, y las diferencias son aún mayores; sólo el ábaco grueso y cuadrado, que cubre por completo el cuerpo del capitel, se puede parangonar, en su concepción global, a los de la ciudad portuaria. Por el contrario, los paralelos más estrechos en el ámbito del capitel jónico se encuentran, como ya se ha indicado, en Segobriga (Trunk, 2008: 28-30), y concretamente en los capiteles atribuidos al segundo orden de la basílica, que han sido fechados en época augustea, ofreciendo por primera vez un contexto arquitectónico a este tipo de capitel. Es curioso también reseñar como en los capiteles de la ciudad celtibérica, el esquema de volutas en doble $\mathrm{S}$ se asocia, en la cara opuesta, a otro distinto, con el canal que une las volutas en forma de una cinta continua que discurre bajo las tres ovas del equino. Esta composición encuentra un confronto inmediato en otra pieza de Zaragoza, con datación augustea (Gutiérrez, 1992: n. 74), que además presenta una palmeta estilizada que surge del enrollamiento de las volutas, motivo presente en los ejemplares de Balcones Azules y calle Honda, donde el tallo brota de la vaina. Paradójicamente, en el Cerro de los Santos, el único capitel que se conoce, aunque sólo a través de un dibujo de Rada y Delgado, fechado a finales de la República o comienzos del Imperio, que debió pertenecer al templo que coronaba el santuario, presenta un estrecho ábaco escalonado y las volutas unidas por un ancho canal en forma de cinta continua con los extremos enrollados, que bordea una única ova situada en el centro (Ramallo, Noguera y Brotons, 1998: 27).

En el marco también de la decoración arquitectónica peninsular ya hemos señalado en otro lugar como paralelo del capitel de la Puerta de la Villa, un capitel custodiado en el Museo Arqueológico de Jaén, en cuyo frente se despliegan volutas espiraliformes. Sobre las inferiores, de las que brotan semipalmetas de cuatro lóbulos, apoya una cabecita humana que ocupa el centro de la composición, detalle que permite incluir esta obra dentro de los llamados capiteles figurados (Gutierrez, 1992: 219). Su cronología se ha situado en época augustea (Gutierrez, 1992: $n^{\circ} 919$ ). Fuera de la Península Ibérica no hemos localizado paralelos inequívocos que se puedan relacionar con los ejemplares hispanos y, más concretamente, con los de Carthago Nova. En el norte de África prácticamente no conocemos capiteles que se encuadren dentro de esta serie. En un ejemplar de Testour encontramos volutas serpentiformes confrontadas horizontalmente aunque dispuestas de forma inversa al de Cartagena, con las espirales menores, que ocupan el centro de la composición, situadas inmediatamente bajo el ábaco, y de su desarrollo surgen las volutas mayores, situadas en los ángulos y en un plano inferior, con una roseta de cuatro pétalos en el centro. Este capitel se fecha hacia finales del siglo I o, incluso, dentro del siglo II d.C.(Ferchiou, 1989: 191, n. VI.III.1), $\mathrm{y}$ al igual que vemos en dos de Cartagena presenta el extremo superior del fuste, rematado por un astrágalo, soldado al capitel. Poco tienen que ver un conjunto de capiteles jónicos de carácter singular recogidos por Romanelli (1970: lám. 210c), procedentes de Gigthis, donde las volutas inferiores han sido reemplazadas por un nudo de Hércules, sobre el que apoya una palmeta vertical que se alza entre las volutas, mientras que el equino se reduce a una hilera de ovas situada en el extremo inferior del capitel. Si volvemos la vista al oriente helenístico, descubrimos en Siria una serie de capiteles jónicos atípicos que, si bien en algunos casos conservan reinterpretados los elementos característicos de capitel jónico clásico, en otros introducen una serie de variantes como es la sustitución del kyma de ovas del equino por una roseta o palmeta vertical en el centro, que 
altera la estructura normal de este tipo de capitel (Dentzer-Feydy, 1990: 154). Vemos pues la dificultad que existe en encontrar referencias precisas dentro del orden jónico para los capiteles de Cartagena, de ahí la complejidad de establecer posibles vías de inspiración, si bien nos parece el ámbito sur-itálico/siciliota en camino más adecuado de transmisión, con una posterior reinterpretación por los canteros de la propia Carthago Nova.

Por el contrario, es en los capiteles corintizantes de época imperial donde se hallan los más cercanos paralelos para el motivo heráldico de la doble cinta serpentiforme y los extremos en espiral. El tema es bien conocido en el mundo griego y aparece ya diseñado en capiteles de Olimpia a finales del siglo $\mathrm{V}$ a.C., donde las volutas exteriores e interiores tienen el mismo tamaño y forma, y con una palmeta que ocupa el centro del kalathos, y dos semipalmetas muy estilizadas que nacen del punto de contacto entre voluta y ábaco (Mallwitz, 1981: 318), o en Delfos, hacia el año 400 a.C. en el orden interno de la tholos del santuario de Atenea Pronea, dispuesto ya sobre una doble corona de hojas de acanto (EAA, Atlante, I, lám. 359, vid. en general, Ronczewski, 1923: 147-158). El tema se retoma en época augustea adaptándolo a diversos soportes. Un paralelo excepcional lo hallamos en la propia Cartagena sobre una placa de mármol blanco de gran tamaño cuya ubicación original aún está por precisar. En consecuencia, es en época imperial cuando hallamos las referencias más cercanas. Así, y dentro de la serie de capiteles corintizantes podemos citar la presencia del esquema con volutas en doble $\mathrm{S}$ en los capiteles del arco de Susa, fechado en el año 9/8 a.C., con una corona de dos grandes hojas de acanto en los ángulos y una palmeta central, que ocupa la mitad inferior del kalathos, sobre la que disponen las cintas espiraliformes trabadas en el centro por un listel sobre el que apoya un palmeta que ocupa el centro de la composición (Gans, 1992, 310, abb. 89). Sobre otro ejemplar conservado en el Museo de Berlín se aprecia la misma disposición, con la corona de hojas de acanto en la mitad inferior y las cintas onduladas terminadas en volutas, divergentes en las exteriores y encontradas en el centro, las interiores, de cuyos giros brotan tres semipalmetas flameantes de tres lóbulos. Flores de cinco pétalos ocupan el óculo de las volutas, mientras que el óvolo del ábaco está recubierto de un kyma jónico (Gans, 1992, 346, Abb. 100). Otra variante se puede ver en el Museo de Nápoles, con semipalmetas flameantes de tres lóbulos que surgen del giro de la espiral (Ronczewski, 1931, Abb, 86). En un capitel corintizante del Antiquarium de Formia, las cintas que determinan las $\mathrm{S}$ son dos grandes hojas de acanto de perfil y encuadradas por listeles en todo en contorno (Gans, 1992, 322, Abb. 95). De un acusado clasicismo es un capitel de pilastra del Antiquarium del teatro de Marcello, con esquema en doble S y palmetas contrapuestas en el centro, mientras que dos flores lotiformes cuelgan del giro exterior de las volutas (Gans, 1992, 314, Abb. 94). El mismo esquema con volutas en $\mathrm{S}$ se reproduce sobre capiteles de los denominados "a sofá", como el de la casa del Fauno de Pompeya (Ronczewski, 1923: 119, fig. 2), y se asocia a capiteles figurados, como en un capitel de pilastra del Museo de Nápoles con águila en lucha con una serpiente entre las volutas y sobre el ábaco (Mercklin, 1962, n. 554, Abb. 1047), así como enmarcando grandes escudos circulares u oblongos, a modo de clípeo, que encuadran un busto (Mercklin, 1962: 126-128, nn. 339-340, "Kapitelle mit Schildbüsten"), fechados en época augustea. En algunas ocasiones, la cinta de las dobles volutas, más estrecha, aparece envuelta por hojas de acanto de perfil y del cáliz, formado en el punto de unión de las volutas inferiores, brota una palmeta de gran tamaño que se superpone al ábaco. Tal es el caso de un capitel de las termas de Antonino en Carthago (Lezine, 1968: 58). Algo más tardíos son los ejemplares de Ostia donde el motivo en doble $\mathrm{S}$ está bien representado sobre capiteles corintizantes (Pensabene, 1973: 220221). Así por ejemplo, en un capitel de pilastra de mármol lunense, fechado en el siglo III, la doble cinta adopta la forma de una gran copa con las volutas inferiores trabadas por el doble cordón atravesado por el tallo de un cáliz del que brota un fruto en forma de espiga (Pensabene, 1973: n. 647, lám. LXI). En otros casos, el esquema se adapta al tipo de corintio asiático, como en un capitel de pilastra, de cronología similar al anterior, donde el espacio intermedio está ocupado por dos hojas de tres lóbulos y el largo tallo ondulado que se remata en la flor del ábaco (Pensabene, 1973: n. 652, lám. LXII). 
En este contexto tan variado y complejo destacan los capiteles jónicos de Cartagena, tanto por su número, en relación a lo que conocemos en otras ciudades hispanas, como por su riqueza ornamental. Los cuatro ejemplares tienen los mismos elementos y motivos ornamentales aplicados sobre la arquitectura del capitel jónico, pero varían, sensiblemente, en el tratamiento. Común es el tema de la doble espiral en $\mathrm{S}$ opuestas y simétricas con la extremidad superior que adopta la función de voluta y las inferiores trabadas en el centro por un listel. En todas las piezas la banda ondulada es ancha en todo su recorrido y sólo se estrecha de forma acusada en el extremo inferior para formar las dos volutas del centro; sin embargo, mientras que en los capiteles de calle Honda y Portmán la sección transversal es continua y ligeramente cóncava, en los otros dos los bordes aparecen realzados y netamente diferenciados. Las semipalmetas flamentes son también distintas, más estilizadas en los capiteles de Puerta de la Villa y Balcones Azules y más regulares y paralelas a las cintas exteriores en Portmán, con una disposición intermedia en el de Honda. También en este caso, la labra es distinta, ya que mientras que en los dos primeros la separación entre lóbulos es mucho más acusada, lo que provoca un juego más intenso de luces y sombras, en los otros dos es más plana. También se diferencian los dos primeros capiteles en el astrágalo o collarino que separa el kalathos del capitel del sumoscapo de la columna, si bien, mientras que en Balcones Azules está decorado con un contario de perlas y discos, en el de la Puerta de la Villa es liso; también en este último la parte de la columna labrada en el mismo bloque es menor que en el de Balcones Azules. En este sentido, quizás se podría relacionar con el capitel de Honda un fragmento de fuste labrado en travertino rojo, hallado en la Plaza de los Tres Reyes (Madrid, 1999: 92), que se remata en el sumoscapo con un grueso collarino de grandes perlas ovoides y discos, muy similar al de Balcones Azules, y que vemos es frecuente en otros capiteles jónicos de Cartagena a finales de la República o comienzos del Imperio. Elemento común es el ábaco en forma de tablero cuadrangular que apoya en sus extremos sobre las volutas y cubre por completo el cuerpo del capitel. Este es un rasgo muy extendido en los capiteles jónicos de Cartagena, y sobre todo en la variante "jónico-itálica", la más numerosa, hasta la fecha, en la ciudad. El borde superior del ábaco aparece decorado con ovas en Calle Honda (Lám. 10) y separadas por lancetas en el de Balcones Azules, mientras que es liso en Portmán; no se puede determinar en el de Puerta de la Villa, al haber desaparecido por completo esta parte. Las diferencias son más acusadas en el motivo que ocupa el eje axial de las caras frontales; mientras que en Portmán se dibuja con claridad una piña cerrada, en Honda es un fruto en forma abellotada sobre una hoja de cuatro anchos lóbulos, en tanto que en Balcones Azules se intuye un fruto en forma de espiga, que nace desde un cáliz ahorquillado. También en la cara frontal es común la existencia de un tallo o palmeta bajo las volutas externas, brote que nace del giro de las volutas, excepto en el capitel de Portmán, que surgen desde las hojas del balteus.

Otras diferencias se manifiestan en el balteus y en la decoración de los rodillos que se desarrollan en las caras laterales. En los tres ejemplares de Cartagena, el balteus adopta la forma de dos hojas de acanto superpuestas, en tanto que el de la Huerta del Paturro presenta también dos hojas superpuestas, pero sólo la superior determina el balteus. Al igual que en la cara frontal, también la labra es distinta en los lados. En Balcones Azules y Puerta de la Villa, la separación entre lóbulos es más profunda, mientras que en Honda es menos acusada. Todos muestran hojas acantiformes en disposición horizontal y contrapuestas (cfr. las variantes en Gutiérrez, 1992: 51). En Balcones Azules, la unión de los lóbulos de acanto determina espacios vacíos en forma de pequeños triángulos y círculos, por el contrario, las hojas de Honda, muy distintas, se caracterizan por sus foliolos apuntados. En relación con el primero hay una voluta con parte del pulvino hallada en las excavaciones del teatro romano que muestra idénticas características y labra tanto en el trabajo de la voluta como en la hoja que recubre el rodillo lateral.

En líneas generales, todos estos capiteles muestran un aire de familia, especialmente los tres de Cartagena, que va más allá del empleo del mismo soporte pétreo y la utilización de los mismos motivos decorativos. Sin embargo, las diferencias entre ellos impiden atribuirlos a una misma mano, aunque si se pueden encuadrar den- 


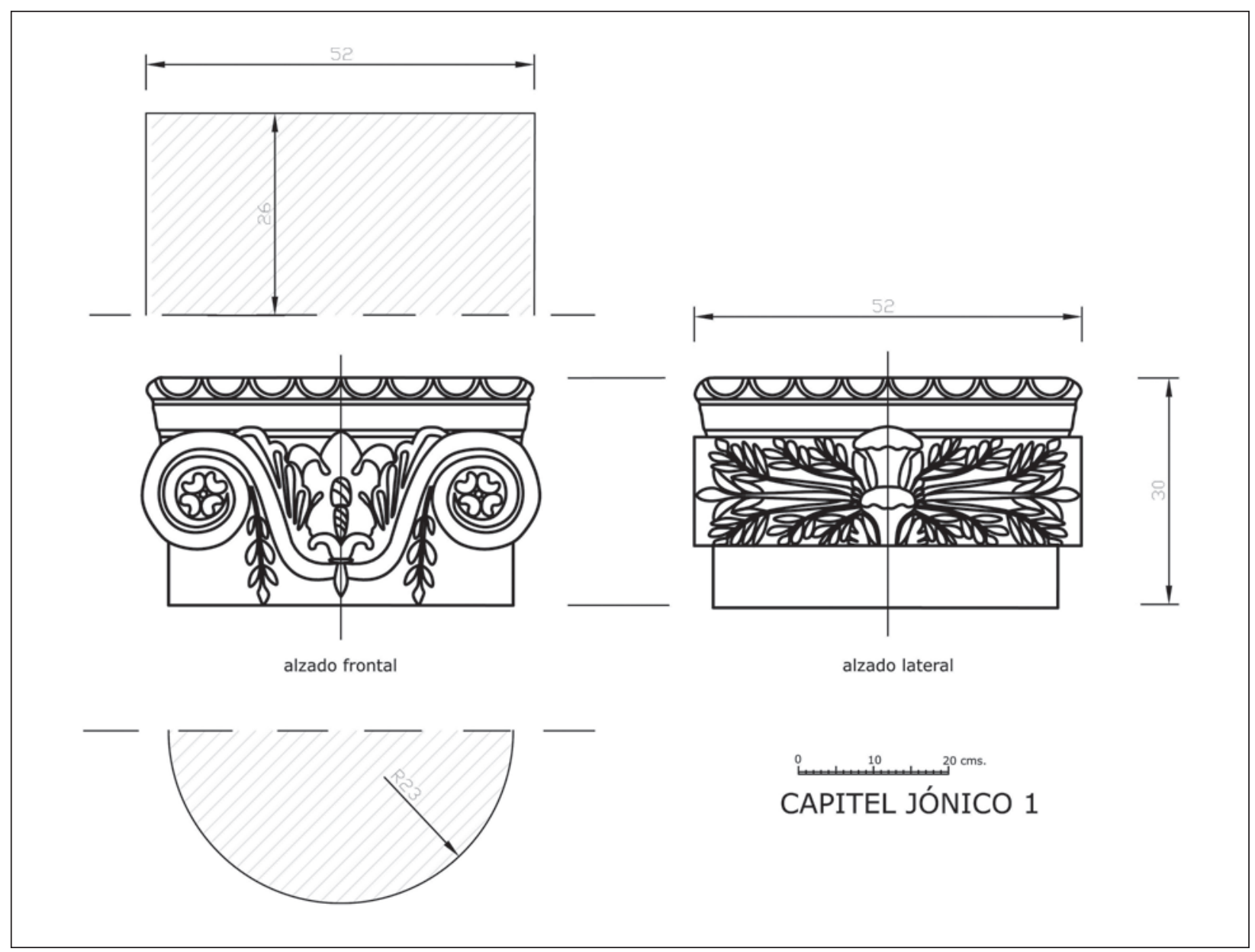

Figura 10.- C/ Honda 7. Alzado frontal y lateral.

tro de la misma tradición. El problema estriba en determinar si todos corresponden a la misma cronología o son de distintos momentos. Ya hemos avanzado más arriba las divergencias que existen entre los diversos autores en la datación del capitel de la Huerta del Paturro, donde el contexto arqueológico sólo permite una atribución genérica a los siglos I y II d.C. Es difícil ir más allá del último cuarto del siglo II d.C., a juzgar por el registro cerámico, que parece marcar una interrupción en el desarrollo de la villa en ese momento. En cuanto a los capiteles de Cartagena, es significativo el tipo de roca utilizado, el travertino rojo, que es característico del proceso de monumentalización de la ciudad a partir de época augustea y que tiene su mejor exponente en las columnas del teatro, inaugurado entre los años 5 y 1 a.C. Por otra parte, el gran apogeo de los talleres jónicos se sitúa entre el último tercio del siglo I a.C. y la primera mitad de la centuria siguiente, datación esta última que podría convenir a nuestros capiteles, a juzgar por el contexto material de
C/Honda -si realmente el capitel jónico corresponde al espacio doméstico- y el paralelismo con los capiteles de la basílica de Segóbriga. Hemos visto, además que el empleo de este esquema en doble $\mathrm{S}$, se halla bien atestiguado en capiteles corintizantes desde época augustea. No obstante, somos conscientes del paralelismo que existe también en algunos de los motivos de los capiteles de Cartagena con los que presentan algunos jónicos del siglo II, e incluso dentro de un momento avanzado del mismo, tal y como sucede con las hojas del pulvino del capitel de calle Honda, que nos llevan a un ejemplar de Útica, probablemente de las termas públicas, en donde el tercio inferior del tronco, separado del equino por un grueso astrágalo está recubierto de un friso con palmetas y hojas, rectas e invertidas, unidas por un cordón serpentiforme (Lezine, 1968: 166, lám. 89-90). Asimismo, la decoración vegetalizada de los pulvinos de Cartagena recuerda las estilizadas hojas de acanto de lóbulos muy alargados que revisten los cojinetes laterales de un capitel figu- 
rado procedente de Sagunto que ha sido fechado, aunque sin argumentos concluyentes, entre los siglos II y III d.C. (Chiner, 1990, 88; Mercklin, 1962: 219, s. II d.C. (?)). En consecuencia, el tema de la datación es un tema abierto que sólo se podrá precisar con hallazgos de capiteles vinculados a contextos bien definidos.

En cualquier caso, los capiteles aquí traídos a colación vienen a ser un testimonio más de la complejidad y variedad que presenta la decoración arquitectónica de Cartagena donde, junto a programas que traducen con fidelidad las nuevas composiciones oficiales desarrolladas a partir de época augustea en la Urbs, nos hallamos con otros que reflejan la convergencia de tradiciones diversas de índole tardo-helenística y que testimonian la vitalidad, y por qué no, creatividad de los talleres de Carthago Nova, una ciudad sometida a influjos de procedencia muy diversa que han cristalizado en esa originalidad que le diferencia de otras poblaciones hispanas. Una diversidad cultural, que arranca de sus mismos orígenes como capital bárquida, y que debió ser una constante a lo largo de su dilatada historia. Un largo recorrido que siempre ha atraído la atención del profesor Bendala, a quien dedicamos esta modesta contribución, como testimonio de nuestra gratitud.

\section{BIBLIOGRAFIA}

ABASCAL PALAZÓN, J. M. Y LORRIO ALVARADO, A. J. (1999): "El miliario de Tiberio de Segobriga y la via Complutum-Carthago Nova", Homenaje al Profesor Montenegro: estudios de historia antigua, Valladolid, 561-568.

DENTZER-FEYDY, J. (1990): "Les chapiteaux ioniques de Syrie méridionale", Syria, LXVII, 143181.

FERCHIOU, N. (1989): L'évolution du décor architectonique en Afrique proconsulaire des derniers temps de Carthage aux Antonins : l'hellénisme africain, son déclin, ses mutations et le triomphe de l'art romano-africain, Gap.

FERNÁNDEZ DÍAZ, A. (1999): La villa romana de Portman: programa decorativo-ornamental y otros elementos para su estudio, Murcia.

FERNÁNDEZ DÍAZ, A. (2003): "Portmán: de villa industrial a villa de recreo", Mastia, 2, 65-107.
FERNÁNDEZ MATALLANA, F., ZAPATA PARRA, J.A. Y TERCERO GARCÍA, J.A., (2007): "Excavación arqueológica de urgencia en la calle número 17 de Cartagena", XVIII Jornadas de Patrimonio Cultural. Intervenciones en el Patrimonio arquitectónico y etnográfico de la Región de Murcia, Murcia, 125-127.

GANS, U. W. (1992): Korinthisierende Kapitelle der römischen Kaiserzeit: Schmuckkapitelle in Italien und den nordwestlichen Provinzen, Köln.

GIMENO PASCUAL, J. (1991): Estudios de arquitectura y urbanismo en las ciudades romanas del nordeste de Hispania, Madrid.

LEZINE, A. (1968): Carthage. Utique. Études d'architecture et d'urbanisme, París.

MADRID BALANZA, M. J. (1999): "El conjunto arqueológico de la plaza de los Tres Reyes (Cartagena). Elementos arquitectónicos", XXIV Congreso Nacional de Arqueología, (Cartagena, 1997), Murcia, 89-95.

MALLWITZ, A. (1981): "Ein Kapitell aus gebranntem Ton oder zur Genesis des korinthischen Kapitells", X. Bericht über die Ausgrabungen in Olympia, Frühjahr 1966 bis Dezember 1976, Berlín, 318-352.

MERCKLIN, E. von (1962): Antike FiguralKapitelle, Berlín.

MOLINA VIDAL, J. (1997): La dinámica comercial romana entre Italia e Hispania Citerior, Alicante.

NOGUERA J. M. ET ALII, (2009): "El foro de Carthago Nova: estado de la cuestión", Fora Hispaniae: paisaje urbano, arquitectura, programas decorativos y culto imperial en los foros de las ciudades hispanorromanas, Murcia, 217-302.

PENSABENE; P. (1973): I capitelli. Scavi di Ostia, 7, Roma.

RAMALLO ASENSIO, S. F. (2004): “Decoración arquitectónica, edilicia y desarrollo monumental en Carthago Nova", La decoración arquitectónica en las ciudades romanas de Occidente, (Cartagena, 2003), Murcia, 153-218.

RAMALLO ASENSIO, S. F. (2009): "Fragmentos para una historia en construcción: la decoración arquitectónica", Arx Hasdrubalis: la ciudad reeencontrada, Catálogo de la exposición, Murcia, pp. 144-152.

RAMALLO ASENSIO, S F., NOGUERA CELDRÁN, J. M. Y BROTONS YAGÜE, F. (1998): “El Cerro de los Santos y la monumentalización de los santuarios ibéricos tardíos", Revista de Estudios Ibéricos, 3, 11-69. 
ROMANELLI, P. (1970): Topografia e archeologia dell'Africa romana, Torino.

RONCZEWSKI, K. (1923): "Variantes des chapiteaux romains. (Materiaux pour l'étude de l'art décoratif)", Annales de l'Université de Latvie, Livr., VIII, 115-174.

RONCZEWSKY, K. (1931): "Römische Kapitelle mit pflanzlichen Voluten”, AA, 1931, coll. 1-101.

SALVI, D. (1992): "Le massae plumbeae di Mal di Ventre"; L'Africa romana IX, (Nuoro, 1991), Sassari, 661-672.
SALVI, D. (1992): "Cabras (Oristanto). Isola di Mal di Ventre: De Carthago Nova verso i porti del Mediterraneo: il naufragio i un carico di lingoti di piombo", Bollettino di Archeologia, 16-18, 237254.

TRUNK, M. (2008): Los capiteles del foro de Segóbriga. Evolución tipológica y estilística, Cuenca. 
